\title{
PERKEMBANGAN SASTRA DI ERA BANI UMAYYAH (ANALISA KRITIS STRUKTURALISME-GENETIK)
}

\author{
Akhmad Muzakki \\ Dosen Jurusan Bahasa dan Sastra Arab, Fakultas Humaniora dan Budaya, \\ Universitas Islam Negeri (UIN) Malang. \\ Jalan Gajayana No. 50 Telepon (0341) 570872, Faksimile (0341) 570872 Malang 65144 \\ Ketua Pusat Kajian Bahasa dan Budaya Fak. Humaniora dan Budaya UIN Malang. \\ Contact Person: HP. 081334701468
}

\begin{abstract}
Sociologically, literature is a reflection of culture environment and as a dialectical text between the author and his social condition. Due to this fact, to understand and interpret literary works, we not only need to know the literary theory but also the external problems, such as, those of religion, society, and politics. In other words, it can be said that a literary work is a very complicated work because basically it is the reflection of human life with various dimensions that influence it.
\end{abstract}

\section{Key words}

Literature, Umayyah, Structuralism, Genetic

\section{Pendahuluan}

Kehadiran Islam di tanah Arab membawa pengaruh dan perubahan, baik terhadap agama, politik maupun keadaan sosial. Bila dalam suatu masyarakat terjadi perubahan seperti itu maka dapat dipastikan akan berpengaruh terhadap corak pemikiran dan bahasa yang dipergunakan. Berkembangnya bahasa-bahasa keagamaan, seperti kata shalat, zakat, puasa, muslim, mukmin, kafir, dan taqwa membawa dampak positif terhadap sikap dan prilaku umat Islam. 
Bahasa keagamaan di atas semakin sering dipergunakan ketika umat Islam memasuki pemerintahan Banî Umayyah. Term mukmin, kafir, musyrik, dan munafik tidak bisa dibendung saat umat Islam terpecah menjadi tiga kelompok besar, yaitu Mu `awiyah, Khawârij dan Syi`ah. Bahasa-bahasa dalam dunia sufi, seperti zuhud, qanâ'ah, mahabbah juga merebak akibat dari sebagian khalifah yang hidup mewah dan berfoya-foya. Munculnya kelompok oportunis yang selalu memuji para pejabat yang berkuasa dan mencaci kelompok lain juga berdampak terhadap perkembangan pemikiran keagamaan.

Semaraknya karya sastra sebagai barang komoditas menjadi fenomena tersendiri yang mewarnai tema-tema yang diekspresikan. Mengutip pernyataan Langland, dikatakan bahwa, "karya sastra merupakan satu refleksi lingkungan budaya dan merupakan satu teks dialektika antara pengarang dan situasi sosial yang membentuknya, atau merupakan penjelasan sejarah dialektik yang dikembangkan dalam karya sastra" (Fananie, 2001:132). Karena itu, usaha untuk mengerti, memahami dan menilai teks sastra tidak hanya bergantung kepada teori sastra saja, tetapi persoalan-persoalan yang terdapat di luar teks, seperti persoalan politik, sosial, agama, dan sebagainya seringkali mewarnai dasar bangunan karya sastra yang diciptakan. Karena pada dasarnya karya sastra merupakan refleksi kehidupan manusia dengan berbagai macam dimensi yang ada (Atmazaki, 1990:59, Semi, 1989:37, Iswanto, 2001:62), bahkan sastra memiliki fungsi psikologis karena mengabadikan pengalaman hidup sastrawan (Fokkema, 1998:22). Seperti dikatakan Husein al-Hâjj Hasan, sastra merupakan potret kehidupan manusia mengenai fenomena ideologi dan tradisinya, makna kecendrungan dan keinginannya, ungkapan cita-cita dan luapan emosinya, serta realitas kepribadiannya (Hasan, 1990:7).

Secara sosiologis, sastra merupakan karya yang bersifat dialektis antara pengarang dan situasi sosial yang melingkari. Berdasarkan pernyataan ini, untuk memperoleh gambaran secara holistik dan komprehensip mengenai perkembangan sastra di era Banî Umayyah maka dalam makalah ini penulis menggunakan metode pendekatan strukturalisme-genetik yang diprakarsai Lucien Goldmann. Pendekatan 
ini dipergunakan untuk melihat, baik aspek-aspek intrinsik sastra itu sendiri maupun aspek-aspek ekstrinsik yang ikut melatarbelakanginya.

\section{Sosio-Kultural Era Banî Umayyah}

Setelah khalifah ketiga, 'Utsmân bin `Affân meninggal dunia `Alî sebagai calon terkuat untuk menduduki khalifah keempat. Tetapi ia mendapat tantangan dari para pemuka, seperti Talhah dan Zubeir dari Mekkah yang mendapat sokongan `Aisyah. Namun tantangan ini dapat dipatahkan oleh `Alî dalam pertempuran di Irak (656 M).

Tantangan kedua datang dari Muawiyah, Gubernur Damaskus dan keluarga dekat 'Utsmân, sebagaimana halnya Talhah dan Zubeir, ia tidak mengakui 'Alî sebagai khalifah. Akhirnya kedua golongan ini mengalami peristiwa yang sama, yaitu peperangan di Siffîn yang banyak makan korban. Kemudian kelompok ketiga tampil, Khawârij yang tidak setuju dengan sikap 'Alî dengan mengambil keputusan arbritase yang pada akhirnya berdampak pada persoalan-persoalan teologis (Nasution, 1986:4).

Dalam sejarah disebutkan, bahwa kekhalifahan Muawiyah diperoleh melalui kekerasan, diplomasi, dan tipu daya, bukan dengan cara yang demokratis. Suksesi kepemimpinan secara turun temurun dimulai ketika Muawiyah mewajibkan seluruh rakyatnya untuk menyatakan setia terhadap anaknya, Yazîd (Mufrodi, 1997:69). Muawiyah bermaksud mencontoh monarki di Persia dan Bizantium. Dia memang tetap menggunakan istilah khalifah, namun dia memberikan interpretasi baru untuk melanggengkan kekuasaannya. Dia menyebutnya "khalîfatullah" dalam pengertian penguasa yang diangkat oleh Allah (Yatim, 2000:42).

Keberhasilan Muawiyah mendirikan dinasti Umayyah bukan hanya akibat dari kemenangan diplomasi di Siffîn dan terbunuhnya khalifah `Alî saja, dari sejak semula Gubernur Suriah ini memiliki "basis rasional" yang solid bagi landasan pembangunan politiknya di masa depan. Pertama, berupa dukungan yang kuat dari rakyat Suriah dan dari keluarga Banî Umayyah sendiri. Kedua, sebagai seorang administrator 
Muawiyah sangat bijak dalam menempatkan para pembantunya pada jabatan-jabatan penting. Ketiga, Muawiyah memiliki kemampuan menonjol sebagai negarawan sejati, bahkan mencapai tingkat "hilm" sifat tertinggi yang dimiliki oleh para pembesar Mekkah zaman dahulu (Mufrodi, 1997:90).

Muawiyah tidak mentaati isi perjanjiannya dengan Hasan bin 'Alî ketika ia naik tahta yang menyebutkan bahwa pergantian kepemimpinan setelah Muawiyah diserahkan kepada umat Islam, sehingga deklarasi pengangkatan Yazîd sebagai putera mahkota menyebabkan munculnya gerakan-gerakan oposisi di kalangan rakyat yang mengakibatkan terjadinya perang saudara.

Ketika Yazîd naik tahta sejumlah tokoh terkemuka di Madinah tidak mau menyatakan setia kepadanya. Kemudian Yazîd mengirim surat kepada gubernur Madinah untuk memaksa semua penduduk mengambil sumpah setia kepadanya. Dengan cara ini ia berhasil membuat penduduk Madinah tunduk kepadanya, kecuali Husein bin ‘Alî dan `Abdullah bin Zubair. Bersamaan dengan itu, kelompok Syi ah melakukan konsolidasi. Perlawanan terhadap Banî Umayyah dimulai oleh Husein. Pada tahun 680 M, Husein pindah dari Mekkah ke Kufah atas permintaan golongan Syi ah yang ada di Irak. Umat Islam di daerah ini tidak mengakui kekhalifahan Yazîd, dan mereka mengangkat Husein sebagai khalifah. Dalam pertempuran yang tidak seimbang di Karbela, tentara Husein kalah, dan Husein sendiri mati terbunuh (Yatim, 2000:45).

Perlawanan orang Syi ah tidak padam dengan terbunuhnya Husein. Bahkan mereka menjadi lebih keras, gigih, dan tersebar luas. Di antaranya adalah pemberontakan Mukhtar di Kufah pada tahun 685-687 M. Ia mendapat banyak pengikut dari kalangan mawâli (umat Islam nonArab, berkebangsaan Persia), Armenia, dan lain-lain yang pada masa Banî Umayyah mereka dianggap warga negara kelas dua. Akhirnya Mukhtar terbunuh dalam peperangan melawan oposisi lainnya, gerakan 'Abdullah bin Zubair. 
'Abdullah bin Zubair membina gerakan oposisinya di Mekkah setelah ia menolak sumpah setia kepada Yazîd. Dan ia menyatakan secara terbuka sebagai khalifah setelah Husein terbunuh. Tentara Yazîd kemudian menggempur Mekkah, peperangan tak terhindarkan sampai akhirnya Yazîd meninggal. Gerakan `Abdullah baru dapat dihancurkan pada masa kekhalifahan 'Abdul Mâlik, di mana tentara Banî Umayyah dipimpin al-Hajjâj.

Selain gerakan di atas, gerakan anarkis lainnya dilancarkan kelompok Khawârij, dan akhirnya golongan Syi ah dapat diredakan. Keberhasilan memberantas gerakan ini yang membuat orientasi pemerintahan dinasti dapat diarahkan kepada pengamanan daerah di wilayah Timur dan Afrika Utara, bahkan membuka jalan untuk menaklukkan Spanyol. Hubungan pemerintahan dengan kelompok oposisi membaik terjadi pada masa kekhalifahan 'Umar bin 'Abdul 'Azîz (717-720 M) (Yatim, 2000:46).

Sepeninggal 'Umar, kekuasaan Banî Umayyah berada di bawah khalifah Yazîd bin `Abdul Mâlik (720-724 M). Penguasa yang satu ini terlalu gandrung dengan kemewahan dan kurang memperhatikan kehidupan rakyat. Masyarakat yang sebelumnya hidup dalam ketentraman, pada zamannya berubah menjadi kacau. Dengan latar dan kepentingan politis, masyarakat menyatakan konfrontasi terhadap pemerintahan Yazîd. Kerusuhan terus berlanjut hingga masa pemerintahan berikutnya, Hisyâm bin `Abdul Mâlik (724-743 M). Pada masa Hisyâm muncul kekuatan baru yang menjadi tantangan berat bagi pemerintahan Banî Umayyah. Kekuatan ini berasal dari kalangan Banî Hâsyim yang didukung mawâli. Dalam perkembangan berikutnya kekuatan ini mampu menggulingkan dinasti Umayyah dan menggatikannya dengan dinasti baru, Banî `Abbâs (Yatim, 2000:47).

\section{Perkembangan Sastra di Era Banî Umayyah}

Dalam periodesasi sejarah sastra ada yang menyebutkan, masa Banî Umayyah dikategorikan ke dalam era shadr al-Islâm (masa permulaan Islam) (Al-Iskandariy, 1978:94). Pada masa ini sastra 
mengalami perkembangan luar biasa yang disebabkan karena pengaruh bahasa agama, yaitu bahasa al-Qur`an dan hadis. Di samping itu, sastra sering kali dipergunakan untuk tujuan penyampaian nilai-nilai ajaran agama(Al-Iskandariy, 1978:96), baik melalui genre syair maupun prosa. Namun yang menarik adalah karya sastra juga dipergunakan untuk kepentingan kelompok (sekte) dan kekuasaan dan bahkan karya sastra menjadi barang komuditas (takassub bi al-syirr) yang senantiasa diperdagangkan.

'Azîz menuturkan, perkembangan sastra di era Banî Umayyah dilatarbelakangi oleh banyak faktor, di antaranya adalah meluasnya daerah Islam dan berkembangnya opini publik beserta sekte-sekte dalam Islam. Misalnya, di Irak muncul tema syair politik (al-syi`r alsiyâsiy), di Syâm genre syair didominasi tema madah (pujian/ode) (AlFaishal, 1402:268). Namun di era Banî Umayyah ada tiga tema sastra yang sangat eksis dan tetap bertahan, yaitu tema al-siyâsiy (politik), naqâidh (polemik), dan syi’r al-futûh wa al-da`wah al-islâmiyyah (perluasan daerah dan dakwah Islamiyyah).

Tema di atas muncul karena diwarnai oleh perpecahan di kalangan umat Islam, yaitu semenjak terjadi peperangan antara golongan `Alî dan Mu 'awiyah yang dikenal dengan peperangan Siffîn. Kemudian tampil golongan ketiga, Khawârij yang tidak setuju dengan sikap 'Alî yang mengambil keputusan arbritase, begitu juga terhadap kubu Mu'awiyah yang melakukan cara licik. Ketika itu masing-masing kelompok memiliki doktrin tersendiri, dan mereka berusaha menarik para penyair untuk mendukung pihaknya dalam menarik masa sebanyak-banyaknya (Al-Taftazani, 1974:64).

Golongan Banî Umayyah adalah golongan yang memiliki kekuasaan, karena itu para penyair yang berada di bawah tekanan politiknya selalu memuji kemuliaan khalifah. Misalnya syair al-Akhthal berikut ini:

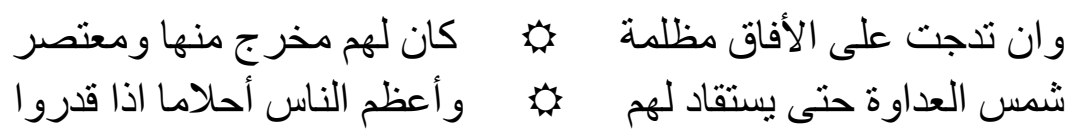


Apabila di ufuk benar-benar gelap gulita

bagi mereka ada jalan keluar dan tempat berlindung

Kesulitan para musuh dapat ditundukkan

jika mereka mampu

mereka adalah manusia yang paling mulya kebijaksanaannya

Melalui syairnya, al-Akhthal memuji kekuasaan Banî Umayyah, ia menceritakan bahwa ketika terjadi kerusuhan dan hiruk pikuk peperangan maka yang dapat memberikan perlindungan dan keselamatan hanyalah kekuasaan Banî Umayyah. Dengan kekuasaan yang diembannya, mereka bisa membantu kepada setiap orang yang membutuhkan pertolongan.

Juga tidak ketinggalan dengan kubu Syi 'ah, salah seorang yang mempertahankan eksistensinya adalah al-Kumait bin Zaid al-Asadiy. Melalui kefasihan lidahnya, ia berusaha mengekspresikan kemuliaan Banî Hâsyim.

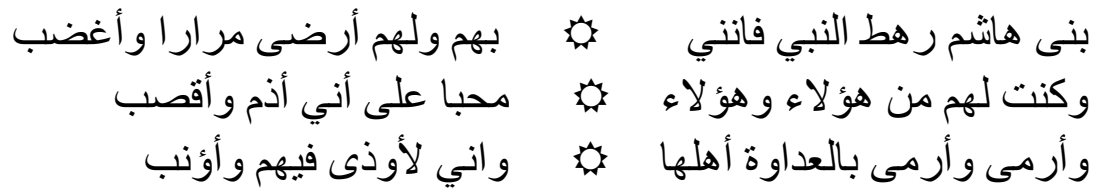

Banî Hâsyim adalah sanak kerabat Nabi

aku selalu bersamanya

aku selamanya rela dan membenci Ban̂̂ Umayyah

Aku mencintai mereka

pada hal aku dicaci dan dicerca

Aku siap berperang untuk mempertahankan keluarganya

dan aku disakiti serta dicela 
Al-Kumait bin Zaid al-Asadiy rela mengorbankan nyawanya untuk membela keluarga Banî Hâsyim, di mana mereka selalu dikucilkan dan dilecehkan Banî Umayyah. Kekuasaan yang menghiasinya dijadikan sarana untuk mendzalimi sekelompok orang yang dianggap tidak sejalan dan menentang kebijakannya. Karena itu, al-Kumait melalui syairnya memberikan semangat dan dorongan kepada Banî Hâsyim untuk melawan Banî Umayyah.

Sementara golongan Khawârij juga melontarkan syairnya dengan mengecam kekuasaan Banî Umayyah, dan mereka berikrar bahwa dinasti Banî Umayyah adalah musuh yang harus dilawan dengan cara apa pun. Seperti syair 'Isâ bin fâtik al-Khatiy (Al-Faishol, 1402:269-270) yang memberikan semangat kepada tentara 'Ubaidillâh bin Ziyâd.

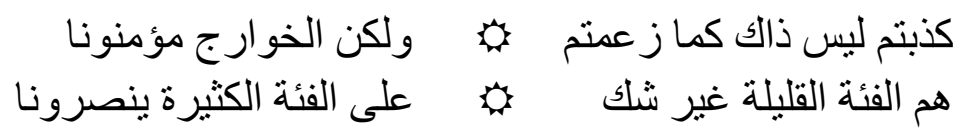

Kalian berdustadan bukan seperti itu yang kalian yakini

Khawârij-lah sekelompok orang-orang yang beriman

Mereka adalah kelompok kecil

yang tidak ada keraguan sedikit pun

terhadap kelompok besar yang selalu dibela

Dalam syair di atas, 'Isâ menggugat kelompok Banî Umayyah karena mereka merasa berada dalam kebenaran. Bagi 'Isâ, kelompok yang benar-benar berpegang pada prinsip al-Qur'an dan beriman sepenuhnya adalah Khawârij. Dan yang menarik dalam syair di atas, dengan kepandaiannya 'Isâ menggunakan bahasa agama, seperti term mu`minûn untuk memberikan justifikasi atas kebenaran paham yang diyakininya.

Persoalan-persoalan yang terjadi dalam lapangan politik pada akhirnya membawa dampak terhadap timbulnya persoalan-persoalan 
teologi. Khawârij memandang 'Alî, Mu'awiyah, 'Amr bin `ash, Abû Musâ al-'Asy'arî, dan lainnya yang menerima arbitrase adalah kafir (Nasution, 1986:6). Munculnya term kafir juga merambah terhadap term-term lainnya, seperti mukmin, murtad, dosa besar, dan sebagainya.

Pada masa dinasti Banî Umayyah banyak terjadi kelaliman dan penindasan terhadap lawan-lawan mereka. Maka wajar kalau hal itu membuat banyak orang cenderung pada asketisisme (zuhud) serta hidup mengisolasi diri (Al-Taftazani, 1974:66). Tokoh sufi, seperti Rabi ah alAdawiyah dengan kosep ridha, taubah dan mahabbah-nya juga muncul di era Banî Umayyah(Al-Taftazani: 84).

Kondisi seperti ini mendorong Qathrî bin Fujâ'ah untuk mengekspresikan khutbahnya guna memberikan nasehat kepada umat Islam agar mereka tidak terlena dengan kemewahan dunia, dan mau mengingat akan kematian. Potongan khutbahnya berbunyi:

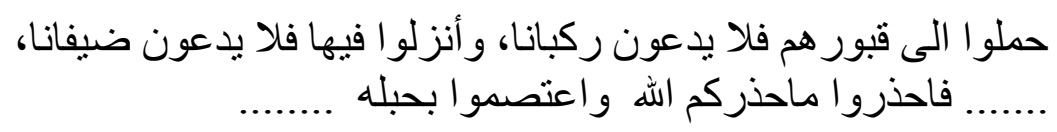

Mereka akan dibawa ke kuburan, kemudian mereka dipanggil tanpa kendaraan. Dan juga mereka diletakkan dalam kuburan, kemudian dipanggil tanpa ada yang menemani...... Hindarilah apa yang dilarang Allah dan berpegang teguhlah kepada agamaNya........(Al-Faishal, 1402:324)

Kemudian tema yang lain adalah tema an-naqầidh (polemik), yaitu seorang penyair yang membangga-banggakan dirinya atau kelompoknya dan mencela kelompok lain. Tema ini menjadi media bagi kelompok yang pro kepada Banî Umayyah untuk mendeskreditkan kelompok yang membangkang. Para penyair yang terkenal dengan tema ini di antaranya ialah Jarîr, Farazdaq, dan Akhthal.

Sementara syi`r al-futûh wa al-da'wah al-islâmiyyah merupakan kelanjutan yang pernah ada pada masa Nabi saw. Di era Banî Umayyah 
perluasan negeri Islam sudah mulai memasuki Andalus, Perancis bagian barat hingga Cina bagian Timur. Syair ini banyak mendeskripsikan tentang jihad di jalan Allah, sehingga para pejuang dituntut untuk bersikap sabar dan penuh keyakinan.

\section{Analisa Kritis Lucien Goldmann: Strukturalisme-Genetik}

Lucien Goldmann menyebut teorinya sebagai strukturalisme-genetik. Artinya, ia percaya bahwa karya sastra merupakan sebuah struktur. Akan tetapi, struktur itu bukanlah sesuatu yang statis, melainkan merupakan produk dari proses sejarah yang terus berlangsung, proses strukturasi dan destrukturasi yang hidup dan dihayati oleh masyarakat asal karya sastra yang bersangkutan. Untuk menopang teorinya, Goldmann membangun seperangkat kategori yang saling bertalian satu sama lain sehingga membentuk apa yang disebutnya sebagai strukturalisme-genetik. Kategori-kategori itu adalah fakta kemanusiaan, subyek kolektif, strukturasi, pandangan dunia, pemahaman dan penjelasan (Faruk, 1999:12).

Strukturalisme-genetik (genetik artinya asal-usul karya sastra) merupakan sebuah pendekatan dalam penelitian sastra yang lahir sebagai reaksi dari pendekatan strukturalisme murni yang anti-historis dan kausal. Atau pendekatan yang hanya memusatkan perhatiannya pada otonomi sastra sebagai karya fiksi. Artinya, menyerahkan pemberian makna karya sastra tersebut terhadap eksistensi karya sastra itu sendiri tanpa mengaitkan unsur yang ada di luar struktur signifikansinya (Iswanto, 2001:61-62).

Dalam sosiologi sastra, karya sastra dipandang sebagai dokumen sosial yang di dalamnya menggambarkan refleksi situasi pada masa sastra tersebut diciptakan. Atau, karya sastra merupakan manifestasi dari kondisi sosial budaya dan peristiwa sejarah. Seperti yang pernah dilakukan Wellek dan Werren, mereka mencoba merumuskan hubungan antara sastra dan masyarakat yang dapat diteliti dengan cara; (a) faktor-faktor di luar teks, dan (b) hubungan antara teks sastra dan masyarakat (Saraswati, 2003:10, Ratna, 2003:2). 
Memperhatikan perkembangan sastra di era Banî Umayyah tidak bisa dilepaskan dengan melihat situasi sosial yang terjadi. Mu'awiyah menjabat khalifah diperoleh dengan cara yang licik, sekalipun ia cakap untuk menjadi pemimpin. Terbentuknya dinasti Banî Umayyah tidak bisa dipisahkan dari konflik-konflik politik yang terjadi di masa 'Alî. Kelompok Syi'ah (pengikut 'Alî) dan Khawârij terus menjadi gerakan oposisi, dan mereka terus mengadakan perlawanan, baik secara fisik maupun pemikiran keagamaan, termasuk bahasa sebagai media.

Karena itu, tidak heran bila perkembangan sastra pada masa Banî Umayyah banyak dimotivasi dan di warnai faktor-faktor politis seperti yang ada pada syair al-Ahkthal, al-Kumait dan Isâ di atas. Bahasa agama sering kali mereka pergunakan untuk menjustifikasi kebenaran kelompoknya, misalnya term-term mu'min, kâfir, fâsiq, dan sebaginya. Seperti yang nampak pada syair Isâ:

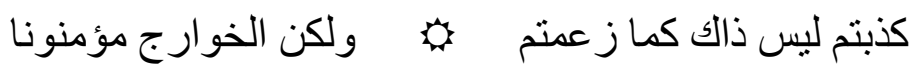

Juga karena kedzaliman penguasa di mana sebagian mereka hidup bermewah-mewah, dan selalu melakukan penindasan terhadap orang yang tidak sepaham maka muncullah bahasa-bahasa sufi, seperti taubah, ridha, mahabbah, zuhud, taqwâ, dan lainnya. Ini menunjukkan bahwa perkembangan bahasa, termasuk sastra tidak bisa dilepaskan dari hegemoni kekuasaan dan kultur-sosial yang melatarbelakangi.

Seperti syair Tsâbit Qathnah (Al-Faishal, 1402:282) yang meminjam bahasa agama "taqwa" berikut ini lantaran kondisi umat Islam terpecah belah demi kepentingan sesaat dengan menggunakan segala macam cara.

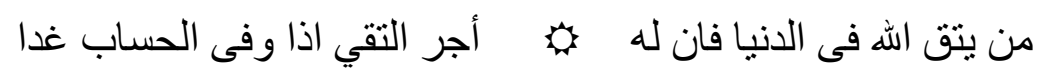

Barang siapa di dunia bertaqwa kepada Allah 
di akhirat ia memperoleh pahala yang mencukupi perhitungan amalnya

Fredric Jameson, tokoh teori Neomarxis mengusulkan interpretasi politik terhadap karya sastra. Dasar pandangannya adalah bahwa setiap teks mengandung resonansi sosial, historis, dan politis. Dengan persepsi bahwa cerita hanyalah permukaan dari sebuah teks yang mengubur sejarahnya yang hakiki, maka pentinglah analisis mengenai ketaksadaran politis dalam teks-teks sastra (Taum, 1997:54).

Dalam lapangan sosial budaya, Banî Umayyah telah membuka kontak antara bangsa-bangsa Muslim (Arab) dengan negeri-negeri taklukan yang terkenal memiliki tradisi yang luhur. Kemudian hubungan ini melahirkan kreatifitas baru yang menakjubkan di bidang seni dan ilmu pengetahuan, termasuk perkembangan berbagai aliran yang tumbuh di masyarakat. Interaksi yang intens dengan negeri-negeri taklukan akan membuka terjadinya assimilasi bahasa dan sekaligus mengenal budaya-budaya lain yang pada akhirnya akan membetuk budaya baru.

Antara bahasa dan budaya terdapat keterkaitan yang sangat erat. Bahasa adalah salah satu alat (media) yang sangat penting dalam mempelajari warisan kebuadayaan. Bahasa terdiri dari simbol atau lambang untuk mengkomunikasikan ide, gagasan, pemikiran dan perasaan kepada orang lain (Maryani, 1997:32). Edward Sapir, seorang antropolog dan linguis, mendukung peryataan bahwa sifat-sifat dasar dan struktur bahasa tertentu merupakan refleksi kebudayaan tempat bahasa itu dipakai. Pandangan dunia suatu masyarakat ditentukan oleh struktur bahasanya, karena bahasa pada umumnya merupakan fenomena kultural (Tarigan, 1986:35). Dengan bahasa seseorang akan memperoleh sikap, nilai-nilai, cara berbuat dan lain sebagainya yang kita sebut dengan kebudayaan. Atau lewat bahasa ia dapat mempelajari pola-pola kultural dalam berpikir dan bertingkah laku dalam masyarakat.

Benyamin Lee Whorf, seorang linguis mengemukakan bahwa bahasa menentukan cara orang berpikir dan bertindak (Haviland, 
1999:394). Bahasa bukanlah sekedar medium atau sarana berpikir belaka, dan bukan pula hanya sekedar "representasi" kenyataan. Secara hakiki bahasa adalah dapat juga kita sebut sebagai manifestasi totalitas pikiran manusia, sebab tidak ada cara lain untuk berpikir tentang hakikat kenyataan itu selain melalui bahasa yang merupakan ungkapan kebudayaan manusia (Kaelan, 1998:186).

Sebab itulah Sapardi Djokodamono dengan mengutip pendapat Grebstein mengungkapkan, bahwa karya sastra tidak dapat dipahami secara komprehensip apabila dipisahkan dari lingkungan atau kebudayaannya (Aminuddin, 2000:47). Jadi budaya atau tradisi yang berkembang di tengah kemajuan Banî Umayyah semenjak menjalin interaksi dengan negeri-negeri taklukan akan berpengaruh terhadap perkembangan sastra. Karena itu, dengan mempelajari perkembangan sastra di era Banî Umayyah kita dapat mengetahui kemajuan budaya, pemikiran, pandangan hidup, sikap, dan prilaku yang ada.

\section{Penutup}

Karya sastra tidak dapat dipahami secara utuh dan komprehensip apabila dipisahkan dari lingkungan yang melatari. Karena antara karya sastra dan kondisi pengarang terjadi hubungan dialektis. Artinya, bahasa tidak muncul dari ruang hampa tanpa ada konteks yang menjadi sebab bahasa itu diekspresikan. Atau, karya sastra merupakan manifestasi dari kondisi sosial budaya dan peristiwa sejarah yang mengitari kehidupan sastrawan.

Melalui pendekatan strukturalisme-genetik dapat dinyatakan bahwa perkembangan sastra di era Banî Umayyah banyak dipengaruhi dan diwarnai oleh faktor-faktor yang berada di luarnya, terutama perkembangan politik. Karena itu, memahami sastra di era ini tanpa melibatkan unsur-unsur ekstrinsik yang melingkupi tidak akan diperoleh satu pemahaman yang holistik. Sastrawan terkenal seperti alAkhthal, Farazdaq dan Jarîr jika diapresiasi secara mendalam maka muatan tema yang ekspresikan banyak menggambarkan situasi sosial (politik) yang terjadi pada masa kekhalifahan Banî Umayyah. $\square$ 


\section{DAFTAR PUSTAKA}

Al-Faishal, `Abd al- 'Azîz bin Muhammad. 1402 H. Al-Adab al-`Arabiy wa Târîkhuhû. Tanpa Penerbit.

Al-Iskandariy, Ahmad dan Musthafâ 'Inâniy. 1978. Al-Wasîth Fî al-Adab al-`Arabiy. Beirut: Dâr al-Ma ârif.

Al-Khaufiy, Ahmad Muhammad. 1965. Adab al-Siyâsah fî al-`Ashr alUmawiy. Beirut: Dâr al-Qalam.

Al-Taftazani, Abu al-Wafa' al-Ghanimi. 1974. Sufi dari Zaman ke Zaman, terj. Ahmad Rofi`Utsmani. Bandung: Pustaka. 
Aminuddin. 2000. Pengantar Apresiasi Karya Seni. Bandung: PT Sinar Baru Algensindo.

Atmazaki. 1990. Ilmu Sastra Teori dan Terapan. Padang: Angkasa Raya.

Endraswara, Suwardi. 2003. Metodologi Penelitian Sastra: Epistemologi,

Model, Teori dan Aplikasi. Yogyakarta: Pustaka Widyatama.

Fananie, Zainuddin. 2001. Telaah Sastra. Surakarta: Muhammadiyah University Press.

Faruk. 1999. Pengantar Sosiologi Sastra: dari Strukturalisme Genetik sampai Post-Modernisme. Yogyakarta: Pustaka Pelajar.

Fokkema, D. W. dan Elrud Kunne Ibsch. 1998. Teori Sastra Abad Kedua Puluh, terj. J. Praptadiharja, judul asli, Theories of Literature in the Twentieth Century. Jakarta: PT Gramedia Pustaka Utama.

Hasan, Husein al-Hâjj. 1990. Adab al-`Arab Fî̀ 'Ashr al-Jâhiliyah. Beirut: Tanpa Penerbit.

Haviland, William A. 1999. Antropologi, terj. R. G. Soekdijo, judul asli, Antropology. Jakarta: Erlangga.

Iswanto. 2001. "Penelitian Sastra dalam Perspektif Strukturalisme Genetik" dalam "Metodologi Penelitian Sastra", ed. Jabrohim. Yogyakarta: PT Hanindita.

Kaelan, M. S. 1998. Filsafat Bahasa Masalah dan Perkembangannya. Yogyakarta: Paradigma.

Maryani, Enok dan Nunung Farida. 1997. Antropolog. Jakarta: PT Grafindo Media Pertama.

Mufrodi, Ali. 1997. Islam di Kawasan Kebudayaan Arab. Jakarta: Logos.

Nasution, Harun. 1986. Teologi Islam Aliran-Aliran Sejarah Analisa Perbandingan. Jakarta: UI Press.

Ratna, Nyoman Kutha. 2003. Paradigma Sosiologi Sastra. Yogyakarta: Pustaka Pelajar.

Saraswati, Ekarini. 2003. Sosiologi Sastra: Sebuah Pemahaman Awal. Malang: UMM Press.

Semi, Atari. 1989. Kritik Sastra. Bandung: Angkasa.

Tarigan, Henry Guntur. 1986. Psikolinguistik. Bandung: Angkasa. 
Taum, Yoseph Yapi. 1997. Pengantar Teori Sastra. Bogor: Nusa Indah.

Yatim, Badri. 2000. Sejarah Peradaban Islam. Jakarta: PT Raja Grafindo Persada. 